\title{
Determinants Of Relationship Continuity Between Sales Representatives And Pharmacists: The Mediating Role Of Trust
}

Abdallah Q. Bataineh, Applied Science Private University, Amman, Jordan

\begin{abstract}
Jordan pharmaceutical sector reflects a complicated multichannel network of pharmaceutical companies (sellers) and pharmacies (buyers). However, the key objective of this study is to investigate the impact of shared values, interdependence, relationship termination costs and emotional intensity (the independent variables) on the expectation of relationship continuity (the dependent variable) between sales representatives of pharmaceutical companies and pharmacists in the Hashemite Kingdome of Jordan, as well as, to explore the role of trust as mediating variable. To achieve that; a self-administered questionnaire has been created and distributed out of a total sample of 500 pharmacies located in the capital of Amman. The findings of the multiple regression tests shown that; emotional intensity is the most influential variable on expectation of relationship continuity, followed by relationship termination costs, shared values and interdependence respectively. Furthermore, trust variable has been found to play a major role as mediating variable. Accordingly, the researcher provided managerial implications and recommendations for upcoming related research.
\end{abstract}

Keywords: Shared Values; Interdependence; Relationship Termination Costs; Emotional Intensity; Trust; Expectation of Continuity

\section{INTRODUCTION}

1 with the customers. Buyers and sellers relationship literatures indicated that there is an unstable and complicated setting between them (Glynn, 2012). According to Nguyen et al., (2007) many organizations have been realized the importance of relational marketing rather than transaction-based marketing. Since loyal customers most likely will generate sales more than the price-sensitive and deal-prone switchers. Moreover, committed relationships are one of the most longlasting, for the reason that they are problematic for competitors to understand or imitate. Therefore, both scholars and practitioners have found that cooperative relationships among buyers and sellers reflect a source of sustainable competitive advantage (Morgan and Hunt, 1994; Cannon and Homburg, 2001; Ulaga and Eggert, 2006).

However, one of the most energetic and promising business sectors in Jordan that are growing at a healthy pace; is the local and multinational pharmaceutical companies, which reflects a rigorous competition between them in manufacturing, marketing and selling their products to their customers which are the retail pharmacies. Based on latest figures provided by Jordan chamber of industry (2014) Jordanian exports of drugs exceeded 623 million JD, which represents around $8 \%$ of the overall Jordanian exports. Furthermore, as a result of the sector's numerous strengths which include competent local human capital and encouraging business environment; the Jordanian pharmaceutical sector is considered to be progressive and one step ahead compared with other regional competitors. Thus, the biggest challenge for pharmaceutical companies is how to market their products and prevent their customers (the retail pharmacies) from switching to another supplier. Therefore, pharmaceutical marketing managers are in need for novel trends in their marketing efforts with their customers, to distinguish themselves from other competitors in the same field. 
Accordingly, this study highlights on the relationship marketing tools and techniques as strategic factors in building solid and long run relationship between buyers and sellers in Jordanian pharmaceutical sector. As well as, the study aims to measure the effect of trust as mediating variable between relationship marketing critical success factors which they are (shared value, interdependence, relationship termination cost and emotional intensity) and relationship continuity. Based on the researcher's best knowledge, a few studies have been conducted in the Jordanian pharmaceutical in business-to-business b2b context. However, the relationship between buyers and sellers requires more examination and analysis in the light of power shifting from sellers to buyers as a result of severe competition (Ali, 2011).

\section{RESEARCH BACKGROUND}

\section{Expectation of Relationship Continuity}

In the beginning of the relationship between buyers and sellers both partners are enthusiastic to invest in the relationship with the intention of benefit from the rewards that are allied with close collaboration, which can be achieved through supportive behaviors from both parties. According to Palmatier et al., (2006) expectation of continuity is defined as company's readiness to retain the relationship with the customers in the future, which can be reflected as repeated purchases from the seller company. Conversely, many researchers have criticized this measure for the reason that customers with poor relational bonds and weak loyalty possibly will show great expectations of continuity as an outcome of their lack of time to appraise alternatives or the perceived switching costs (Oliver, 1999). Nevertheless, supportive behaviors from buyers and sellers can enhance collaboration, overcome problems through mutual solutions, increase commitment and relationship continuity (Basheka, 2007). Thus, relationship continuity can be resulted from other factors during any phase of the relationship building process, which starting with customer's acquisition and ending with customer's retention.

\section{Shared Values}

The overall beliefs among buyers and sellers in terms of what goals, behaviours, terms and policies are significant or insignificant, suitable or unsuitable, correct or incorrect; is termed as shared values (Morgan and Hunt, 1994). However, the concept of shared values can be described as social contract appears during preliminary stage of the relationship development and shape the rules and guidelines for upcoming exchange. According to Dwyer et al., (1987) when buyers and sellers share common vision or goals, they will be ready to assign roles between each other when needed. Therefore, shared values consider as precious antecedents of both trust and relationship continuity between sales representatives of pharmaceutical company and retail pharmacist. In view of that, the following hypothesis can be proposed:

H1: Shared values positively impacts expectation of relationship continuity between sales representatives and pharmacists.

\section{Interdependence}

In general, buyers and sellers work to keep up their relationship and avoid damaging activities. The degree of buyers' dependence on the seller found to be a critical factor that positively influences financial and non-financial satisfaction of the buyers (Chung et al., 2007). Moreover, the level of dependence increased if the needed outcomes are highly valued by the exchange partners. Nevertheless, the conditions of dependence change in the light of the relationship setting, which might not always to be happened (Morgan and Hunt, 1994). According to Laaksonen et al., (2008) interdependence can decrease the opportunistic behaviours by sellers. Hence, pharmacist's interdependence on sales representatives might be associated with the expectation of relationship continuity. In view of that, the following hypothesis can be proposed:

H2: Interdependence positively impacts expectation of relationship continuity between sales representatives and pharmacists. 


\section{Relationship Termination Costs}

For decades, the switching barriers have been used as marketing weapon to create restrictions for buyers to switch to another company. According to Fornell (1992) these barriers include searching costs, transaction conducting costs, learning costs, discounts for loyal buyers and even emotional costs. Furthermore, buyer satisfaction can't precisely predict the relationship continuity (Curasi and Kennedy, 2002). Relationship termination costs reflects the overall losses which they are expected from ending any relationship, as well as; lack of alternatives, weak communications and distrust have been found of a vital effect on terminating the relationship (Morgan and Hunt, 1994). Thus, relationship continuity can be a result of high or low termination costs for both sales representatives and pharmacists. In view of that, the following hypothesis can be proposed:

H3: Relationship termination costs positively impacts expectation of relationship continuity between sales representatives and pharmacists.

\section{Emotional Intensity}

Individuals' Emotional attachment for each others can powerfully influence them to participate, co-produce and spend more time and efforts in building and sustaining their relationships. The term emotional intensity in $\mathrm{b} 2 \mathrm{~b}$ context can be described as the buyers and sellers feelings toward each other's away from the financial benefits caused by a given transaction (Stanko et al., 2007). In addition, using social bonds for managing relationships highly related with deeprooted norms for courtesy, honesty and fairness (Gilliland and Bello, 2002). Consequently, sales representatives and pharmacists real emotional attachment for each other and beyond the official business relationship might lead to longer relationships. In view of that, the following hypothesis can be proposed:

H4: Emotional intensity positively impacts expectation of relationship continuity between sales representatives and pharmacists.

\section{Trust}

The groundwork of trust researches has been started during late 80's and early 90's (e.g. Dwyer et al., 1987; Morgan and Hunt, 1994;). Trust has been described as confidence in the providers' integrity, reliability and performance (Morgan and Hunt, 1994). Previous researches viewed trust as multidimensional concept, for instance credibility and benevolence (e.g. Doney and Canon, 1997); integrity, honesty, competence, goodwill; constancy (e.g. Kenning, 2008); reliability (e.g. Svensson, 2005); fairness; predictability (e.g. Zaheer et al., 1998). However, trust is a crucial construct in building and developing relationships between buyers and sellers, the critical meaning and implication of trust is varying from trusting product, company or person. Hence, building trust bridges between sales representatives and pharmacists might be the cornerstone for enduring relationship. In view of that, the following hypothesis can be proposed:

H5: the impact of shared values, interdependence, relationship termination costs and emotional intensity on expectation of relationship continuity between sales representatives and pharmacists will be mediated by trust.

\section{CONCEPTUAL MODEL}

Based on thorough analysis of relevant literatures; the following conceptual model has been developed, which essentially derived from the antecedents of relationship marketing theories and practices. 
Figure 1. Conceptual Model

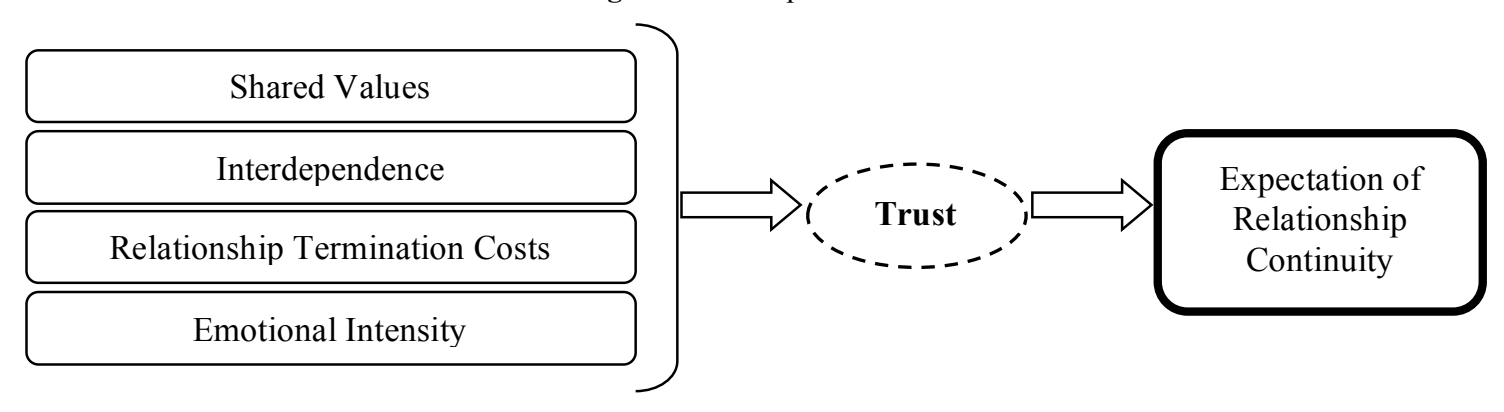

RESEARCH METHODOLOGY

\section{Population and Sample}

According to recent figures provided by Jordanian ministry of health (2014) the number of registered pharmacies in Jordan is 2298 , more than $55 \%$ of them are located in the capital of Amman, and the others are distributed among the other counties. However, the research population consists of all retail pharmacies operating in Jordan. Since the capital of Amman contains the highest share of retail pharmacies, and reflects somehow representative geographic sample in terms of pharmacies intensity and diversity; the researcher has used convenience sampling technique to collect data from the research respondents, which they are the (authorized pharmacists) working at the retail pharmacies in Amman, who are in frequent contact with the sales representatives of pharmaceutical companies. Moreover, in order to have statistical stability analysis; the size of the sample was determined to be 500 authorized pharmacists in the capital of Amman; and that was identified by Hair et al., (2010) depending on the number of items in the research questionnaire. The researcher relied on the contact list of pharmacies available on Jordanian pharmaceutical association official website (2016) in order to arrange suitable method for pharmacists to fill up the research questionnaire. However, the researcher used both fieldwork and online channels to spread out the research questionnaires based on the favorable way by pharmacists. Even though, after than three months of distribution process; only 366 questionnaires were retrieved and considered valid for the use in statistical analysis. As a result, the response rate $73.2 \%$ was to some extent high.

\section{Research Instrument and Data Gathering}

To facilitate gathering data from pharmacists; the researcher has developed the research instrument based on previous works related to the antecedents of relationship marketing and relationship continuity from b2b perspective. Likewise, five-points Likert' scale were also applied. Hence, research operational definitions and measurements have been adapted from the following preceding studies.

Table 1. Research measurements

\begin{tabular}{l|l}
\hline \multicolumn{1}{c}{ Variable } & \multicolumn{1}{c}{ Measurement } \\
\hline Shared values & Dwyer et al., (1987) \\
\hline Interdependence & Laaksonen et al., (2008) \\
\hline Relationship termination costs & Morgan and Hunt (1994) \\
\hline Emotional intensity & Stanko et al., (2007) \\
\hline Trust & Morgan and Hunt (1994) \\
\hline Expectation of continuity & Palmatier et al., (2006) \\
\hline
\end{tabular}

\section{Research Validity and Reliability}

The research instrument validity was tested through face validity and content validity identified in (Churchil and brown, 2014). Face validity has been tested based on pilot study conducted with qualified and well-known figures from the pharmaceutical sector in Jordan who have deep experience in this field, whereas the content validity was assessed by the methodological approaches which have been applied in previous works as mentioned in the prior section. Furthermore, cronbach's alpha test has been used to assess the research instrument reliability, and that was identified 
by (Sekaran and Bougie, 2013). However, as demonstrated in table 2 below; all of the research variables have a value greater than the cutoff point used in this research which is $60 \%$. Thus, the internal reliability coefficients were met.

Table 2. Values of Cronbach's alpha test

\begin{tabular}{l|c|c}
\hline \multicolumn{1}{c|}{ Variables } & Number of Items & Cronbach's Alpha \\
\hline Shared values & 4 & 0.788 \\
\hline Interdependence & 3 & 0.741 \\
\hline Relationship termination costs & 6 & 0.865 \\
\hline Emotional intensity & 4 & 0.873 \\
\hline Trust & 6 & 0.847 \\
\hline Expectation of continuity & 5 & 0.896 \\
\hline
\end{tabular}

\section{DATA ANALYSIS}

\section{Demographic Characteristics}

Table 3 illustrates respondents' demographic characteristics. However, for the first three categories gender, age and educational level; they are all consistent with the (2015) figures provided by Jordanian pharmaceutical association. Likewise, the 3-6 years category has the highest share, which noticeably indicates that pharmacists for a great extent have good experience.

Table 3. Demographics characteristics

\begin{tabular}{|c|c|c|}
\hline Variable & Frequency & Percentage\% \\
\hline \multicolumn{3}{|l|}{ Gender } \\
\hline Male & 244 & 66.7 \\
\hline Female & 122 & 33.3 \\
\hline \multicolumn{3}{|l|}{ Age category } \\
\hline Less than 26 & 64 & 17.6 \\
\hline $26-34$ & 133 & 36.3 \\
\hline $35-44$ & 99 & 27.0 \\
\hline More than 44 & 70 & 19.1 \\
\hline \multicolumn{3}{|l|}{ Educational level } \\
\hline Bachelors' & 272 & 74.3 \\
\hline Masters' degree & 77 & 21.0 \\
\hline Doctoral' degree & 17 & 4.7 \\
\hline \multicolumn{3}{|l|}{ Number of Experience years } \\
\hline Less than 3 & 104 & 28.4 \\
\hline $3-6$ & 126 & 34.5 \\
\hline $7-10$ & 88 & 24.0 \\
\hline More than 10 & 48 & 13.1 \\
\hline Total & 366 & 100.0 \\
\hline
\end{tabular}

\section{Hypothesis Testing}

With the aim of testing the research hypothesis; the researcher has applied multiple regression models to analyze the impact of shared value, interdependence, relationship termination cost and emotional intensity on expectation of relationship continuity, As well as, exploring the mediating effect of trust.

H1: Shared values positively impacts expectation of relationship continuity between sales representatives and pharmacists. 
As shown in table 4 , shared values variable can positively and significantly impact expectation of relationship continuity. Furthermore, $(53.7 \%)$ of the variation in expectation of relationship continuity can be interpreted by shared values, and the beta value $=0.733$ is significant at $(0.000)$. Thus, $\mathrm{H} 1$ is supported.

\begin{tabular}{|c|c|c|c|c|c|}
\hline $\mathbf{R}$ & $\mathbf{R}^{2}$ & $\mathbf{F}$ & Sig. & \multirow{2}{*}{\multicolumn{2}{|c|}{$\begin{array}{l}\text { H1 Result } \\
\text { Supported }\end{array}$}} \\
\hline $.733 \mathrm{a}$ & .537 & 191.905 & $.000 \mathrm{~b}$ & & \\
\hline \multicolumn{6}{|l|}{ Coefficients } \\
\hline \multicolumn{2}{|c|}{ Unstandardized Coefficients } & \multicolumn{2}{|c|}{ Standardized Coefficients } & & \\
\hline B & Std. Error & \multicolumn{2}{|c|}{ Beta } & $\mathbf{T}$ & Sig. \\
\hline 2.664 & .117 & \multirow{2}{*}{\multicolumn{2}{|c|}{.733}} & 16.567 & .000 \\
\hline .227 & .022 & & & 13.853 & .000 \\
\hline
\end{tabular}

* Significance level at $\mathrm{P} \leq 0.05$

H2: Interdependence positively impacts expectation of relationship continuity between sales representatives and pharmacists.

As shown in table 5, interdependence variable can positively and significantly impact expectation of relationship continuity. Furthermore, $(27.7 \%)$ of the variation in expectation of relationship continuity can be interpreted by interdependence, and the beta value $=0.527$ is significant at $(0.000)$. Thus, $\mathrm{H} 2$ is supported.

Table 5. Multiple regression test for $\mathrm{H} 2$

\begin{tabular}{|c|c|c|c|c|c|}
\hline $\mathbf{R}$ & $\mathbf{R}^{2}$ & $\mathbf{F}$ & Sig. & \multicolumn{2}{|c|}{ H2 Result } \\
\hline $.527 \mathrm{a}$ & .277 & 138.133 & $.000 \mathrm{~b}$ & \multicolumn{2}{|c|}{ Supported } \\
\hline \multicolumn{6}{|c|}{ Coefficients } \\
\hline \multicolumn{2}{|c|}{ Unstandardized Coefficients } & \multicolumn{2}{|c|}{ Standardized Coefficients } & & \\
\hline B & Std. Error & \multicolumn{2}{|c|}{ Beta } & $\mathbf{T}$ & Sig. \\
\hline 3.115 & .271 & \multirow{2}{*}{\multicolumn{2}{|c|}{.527}} & 15.134 & .000 \\
\hline .333 & .035 & & & 11.753 & .000 \\
\hline
\end{tabular}

* Significance level at $\mathrm{P} \leq 0.05$

H3: Relationship termination costs positively impacts expectation of relationship continuity between sales representatives and pharmacists.

As shown in table 6, relationship termination costs variable can positively and significantly impact expectation of relationship continuity. Furthermore, $(64.1 \%)$ of the variation in expectation of relationship continuity can be interpreted by relationship termination costs, and the beta value $=0.801$ is significant at $(0.000)$. Thus, $\mathrm{H} 3$ is supported.

Table 6. Multiple regression test for $\mathrm{H} 3$

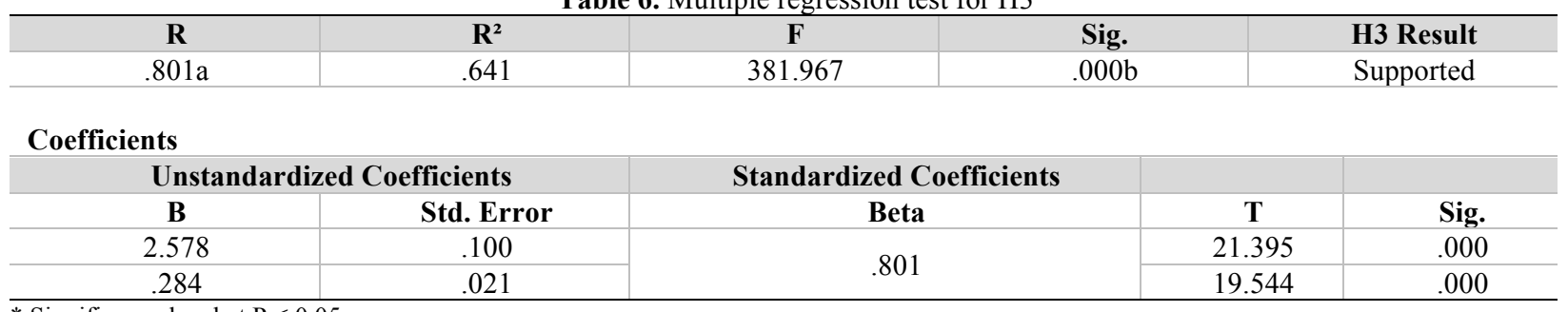

* Significance level at $\mathrm{P} \leq 0.05$ 
H4: emotional intensity positively impacts expectation of relationship continuity between sales representatives and pharmacists.

As shown in table 7 emotional intensity variable can positively and significantly impact expectation of relationship continuity. Furthermore, $(69.7 \%)$ of the variation in expectation of relationship continuity can be interpreted by emotional intensity, and the beta value $=0.835$ is significant at $(0.000)$. Thus, $\mathrm{H} 4$ is supported.

Table .7 Multiple regression test for $\mathrm{H} 4$

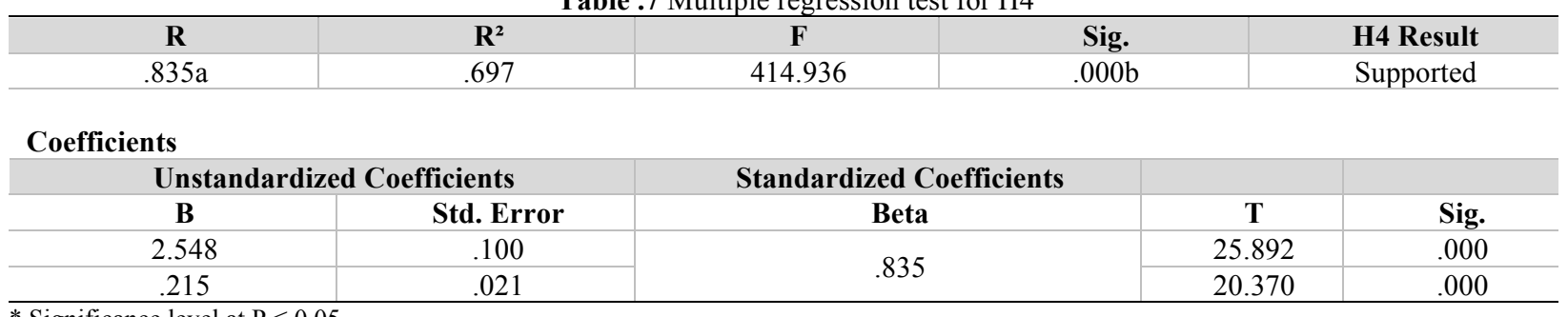

* Significance level at $\mathrm{P} \leq 0.05$

H5: The impact of shared values, interdependence, relationship termination costs and emotional intensity on expectation of relationship continuity between sales representatives and pharmacists will be mediated by trust.

Table 8 illustrates that $76.3 \%$ of the variation in expectation of relationship continuity can be explained by the independent variables shared values, interdependence, relationship termination costs and emotional intensity. Accordingly, the regression results of weighted least square test (WLS) showed that emotional intensity and relationship termination costs are respectively the strongest predictors based on beta values. Moreover, the value of $\mathrm{R}^{2}$ is greater than the $\mathrm{R}^{2}$ values in the preceding tables, which means that the impact of shared values, interdependence, relationship termination costs and emotional intensity on expectation of relationship continuity can be stronger throughout trust as mediating variable. Therefore, the overall findings support accepting H5.

Table 8. Weighted least square test (WLS) in the regression model for H5

\begin{tabular}{c|c|c|c|c}
\hline $\mathbf{R}$ & $\mathbf{R}^{\mathbf{2}}$ & $\mathbf{F}$ & Sig. & H5 Result \\
\hline $.874 \mathrm{a}$ & .763 & 336.318 & $.000 \mathrm{c}$ & Supported \\
\hline
\end{tabular}

\section{Coefficients}

\begin{tabular}{l|c|c|c|c|c|c} 
& Unstandardized Coefficients & Standardized Coefficients & T & Sig. \\
\hline (Constant) & B & Std. Error & Beta & .000 \\
\hline Shared values & 2.381 & .129 & & .366 & 1.246 & .000 \\
\hline Interdependence & .185 & .024 & .321 & 1.188 & .000 \\
\hline Relationship termination costs & .143 & .019 & .365 & 1.593 & .000 \\
\hline Emotional intensity & .169 & .032 & .393 & 1.871 & .000 \\
\hline
\end{tabular}

* Significance level at $\mathrm{P} \leq 0.05$

\section{DISCUSSIONS AND MANAGERIAL IMPLICATIONS}

As demonstrated in the preceding tables; all hypotheses were supported empirically. The overall results of the multiple regression tests indicated that all independent variables including shared values, interdependence, relationship termination costs and emotional intensity have significant impact on expectation of relationship continuity between sales representatives and pharmacists. Otherwise, pharmacists trust in sales representatives has shown essential effect as mediating variable. However, these outcomes were in line with the previous literatures of relationship marketing. However, the most effective and significant variable that impact expectation of relationship continuity was emotional intensity. Accordingly, this finding seems consistent with (Stanko et al., 2007; Gilliland and Bello, 2002), and 
respectively; relationship termination costs was consistent with (Morgan and Hunt, 1994), shared values consistent with (Dwyer et al., 1987; Morgan and Hunt, 1994), and interdependence was consistent with (Laaksonen et al., 2008). In addition, the mediating role of trust variable has been clearly supported based on the (WLS) test, which was in line with (Morgan and Hunt, 1994; Kenning, 2008). Hence, this study is important for pharmaceutical companies for the following reasons: (1) leveraging the relationship with pharmacists from official bond to social bond hinges on integrity, honesty and reliability of sales representatives; (2) retaining pharmacists in the future can be resulted from increasing the overall costs from the relationship, through long supply contract with fair prices and extraordinary communications and services; (3) for a great extent both sales representatives and pharmacists have shared values, derived from the overall paradigm of Jordanian culture, which reflects transparency and generosity for most citizens; finally, (4) although some pharmaceutical companies have a real competitive advantage in their products; but it can be easily imitated by internal or external suppliers, which leads them to build up solid and distinguish relationships with pharmacies as the cornerstone to win them as repeated and patronage customers in the future.

\section{RECOMMENDATIONS AND FUTURE RESEARCH}

The main goal of marketing in $b 2 b$ or $b 2 c$ context is not only to make profits, but to keep up a long-term relationship with the customers (Gounaris, 2005). Therefore, the current study offers a broad understanding of the antecedents and consequences of critical success factors in managing the relationship marketing within $\mathrm{b} 2 \mathrm{~b}$ context. However, although pharmaceutical companies in Jordan are spending huge marketing efforts to attract and maintain pharmacies; applying relationship techniques might be as trade secret to select, serve and retain high share of pharmacies. Moreover, creating rich and retrievable database about pharmacies and pharmacists can make it easier for pharmaceutical companies to choose the most appropriate tools and marketing weapons to serve them better than other players in the market. On the other hand, developing trust bridges with pharmacists will lead to enhance the company image, and make pharmacists to spread free promotional messages about it.

Future researches could investigate other variables that influence relationship continuity, or to use the study model in different b2b context. Finally, other researchers can make a comparison between local and foreign pharmaceutical supplier's practices in terms of the applied relationship marketing strategies and techniques.

\section{ACKNOWLEDGEMENT}

The author is grateful to the applied science private university, Amman, Jordan, for the full financial support granted to this research project (DRGS-2015-2016-50).

\section{AUTHOR BIOGRAPHY}

Dr. Abdallah Q. Bataineh received a Bachelor degree in Marketing from the Applied Science Private University in 2006. Upon graduation he completed an MBA in marketing from the Arab Academy for Banking and Financial Sciences in 2008. He next worked as marketing consultant at Samsung Corporation for three years, and he has finished his PhD study in Amman Arab University in 2012, and he is currently Associate Professor (full time lecturer) and the head of the marketing department at Applied Science Private University from 2013.

\section{REFERENCES}

Ali, Md. B. (2011), Antecedents of Supplier-Retailer Relationship Commitment: An Empirical study on Pharmaceutical Products in Bangladesh. Journal of Economics and Sustainable Development, 2(7), 8-19.

Basheka, B. (2007) “Advancing Public Procurement: Practices, Innovation and Knowledge Sharing”, The case for Public Entities in Uganda: Paper presented at the 4th International Public Procurement Conference, October 21-23, Fort Lauderdale, Florida, USA.

Cannon, J. P. and Homburg, C. (2001), "Buyer-supplier relationships and customer firm costs," Journal of Marketing, Vol 65 January, pp. 29-43.

Churchill, GA \& Brown TJ. (2014). Basic Marketing Research (8th ed.). Cengage Learning.

Curasi, C.F., K.N. Kennedy. From Prisoners to Apostles: A Typology of Repeat Buyers and Loyal Customers in Service Businesses, The Journal of Service Marketing, 2002. - Vol. 16, No. 4. - pp. 322-342.

Doney, P.M. and Cannon, J.P. (1997). An Examination of the Nature of Trust in Buyer-Seller Relationships. Journal of 
Marketing, 61(2), 35.

Dwyer, F.R., Schurr, P.H and Oh, S. (1987). Developing Buyer- Seller Relationships, Journal of Marketing, $51(2), 11$.

Fornell, C. A National Customer Satisfaction Barometer: The Swedish Experience, Journal of Marketing, 1992. - Vol. 56, January. - pp. 6-21.

Gilliland, D. I. and Bello, D.C. (2002). Two Sides to Attitudinal Commitment: The Effect of Calculative and Loyalty Commitment on Enforcement Mechanisms in Distribution Channels. Journal of the Academy of Marketing Science, 30(1), 24-43.

Glynn, Mark S., Brodie, Roderick J., Motion, Judy (2012), The benefits of manufacturer brands to retailers. European Journal of Marketing, 46(9). 1127-1149.

Gounaris, S.P. (2005). Trust and Commitment Influences on Customer Retention: Insights from Business-to-Business Services. Journal of Business Research, 58(2005), 126-140.

Hair, J.F., Jr., Black, W.C., Babin, B.J. \& Anderson, R.E. (2010). Multivariate Data Analysis. 7th ed., Prentice Hall, Upper Saddle River, N.J.

Kenning, P. (2008). The Influence of General Trust and Specific Trust on Buying Behaviour. International Journal of Retail \& Distribution Management, 36(6), 461-476.

Laaksonen, T., Pajunen, K. and Kulmala, H.I. (2008). Coevolution of Trust and Dependence in Customer Supplier Relationships. Industrial Marketing Management, 37, 910-20.

Morgan, R. M. and Hunt, S. D. (1994), “The commitment-trust theory of relationship marketing,” Journal of Marketing, Vol 58 July, pp. 20-38.

Nguyen, T. M. T., Barrett, N. J. and Nguyen, T. D. (2007), “The role of market and learning orientations in relationship quality Evidence from Vietnamese exporters and their foreign importers", Advances in International Marketing, Vol 17, pp. 107-133.

Oliver, Richard L. (1999), “Whence Consumer Loyalty?” Journal of Marketing, 63 (Special Issue), 33-44.

Palmatier, R.W., Dant, R.P., Grewal, D. and Evans, K.R. (2006). Factors Influencing the Effectiveness of Relationship Marketing: A Meta-Analysis. Journal of Marketing, 70 (October), 136-153.

Ulaga, W. and Eggert, A. (2006), "Value-based differentiation in business relationships: Gaining and sustaining key supplier status," Journal of Marketing, Vol 70 January, pp. 119-136.

Oliver, Richard L. (1999), "Whence Consumer Loyalty?” Journal of Marketing, 63 (Special Issue), 33-44.

Sekaran, U., Bougie, R. (2013). Research Methods for Business (6th ed.). John Wiley \& Sons, Inc.

Stanko, M.A., Bonner, J.M. and Calantone, R. J. (2007). Building Commitment in Buyer-Seller Relationships: A tie Strength Perspective. Industrial Marketing Management, 36 (2007), 1094-1103.

Svensson, G. (2005). Mutual and Interactive Trust in Business Dyads: Condition and Process. European Business Review, 17(5), 411-427.

Zaheer, A., McEvily, B. and Perrone, V. (1998). Does Trust Matter? Exploring the Effects of Inter-organizational and Interpersonal Trust on Performance. Organization Science, 9(2), 141.

http://www.jci.org.jo

http://www.jpa.org.jo

http://www.moh.gov.jo 


\section{NOTES}

